Portland State University

PDXScholar

\title{
A Buddhist-Informed Conceptual Framework for Compassion Fatigue Prevention
}

Andrei A. Agapi

Portland State University

Follow this and additional works at: https://pdxscholar.library.pdx.edu/honorstheses

Part of the Buddhist Studies Commons, and the Psychology Commons Let us know how access to this document benefits you.

\section{Recommended Citation}

Agapi, Andrei A., "A Buddhist-Informed Conceptual Framework for Compassion Fatigue Prevention" (2021). University Honors Theses. Paper 987.

https://doi.org/10.15760/honors.1011

This Thesis is brought to you for free and open access. It has been accepted for inclusion in University Honors Theses by an authorized administrator of PDXScholar. Please contact us if we can make this document more accessible: pdxscholar@pdx.edu. 


\author{
by \\ Andrei Agapi \\ An undergraduate honors thesis submitted in partial fulfillment of the requirements for the \\ degree of \\ Bachelor of Arts \\ In \\ University Honors and Psychology
}

Thesis Adviser:

Leigh Miller, $\mathrm{PhD}$

Portland State University 2020 


\section{ABSTRACT}

The purpose of this thesis is to present Buddhist meditation practices and modes of investigation that can mitigate compassion fatigue, some of which have not yet been acknowledged in this research field. Conducting a literature review, I found multiple frameworks for compassion fatigue that have different and sometimes contradictory causes, and a lack of clear differentiation between sympathy, empathy and compassion. Both of these aspects are explored. I explain the Buddhist approach to compassion, and the cause of fatigue from a Yogachara philosophical perspective. Then, I write about a bodhisattva's training in no-self, the five-aggregate model of mind, Chenrezig practice, and tonglen. Some researchers propose compassion fatigue is caused because engagement in compassion drains internal resources, others write that incomplete engagement of compassion is in actuality the reason behind it, while some look at numerous other motives outside this primary split. The problem in this field of research is a lack of consensus regarding the causes for compassion fatigue, a multitude of other terms (vicarious traumatization, secondary traumatic stress disorder, burnout) that seem point to the same experience, and a lack of clear differentiation between compassion, empathy and sympathy. The Buddhist explanation for compassion fatigue takes into account all the seemingly contradictory stances, and several Buddhist practices are briefly explained and proposed as mitigators. It is hoped this study provides further awareness of the problematic nature of the term “compassion fatigue", and generates interest for further research into Buddhist practices of meditation, visualisation and investigation that have not yet been explored for their capacity for mitigation of compassion fatigue. 


\section{Preface: personal story}

My interest in Buddhism began concomitantly with starting a job in a local youth shelter, my first job where I was exposed to a constant influx of human suffering. My job involved doing intakes and being around youth from emotionally or physically abusive families, from families in environments of drug abuse or domestic violence, and overall children that were not offered environments in which they could thrive. Although these two began simultaneously, it took time for the integration of my meditation practice in my work, which benefited both immensely. In the beginning, listening to the stories of my clients provoked me physical and emotional discomfort, a depletion of physical and emotional energy, disruptions in my core beliefs, spirituality, a loss of hope, purpose and meaning. I experienced, then, compassion fatigue, burnout, or vicarious traumatization. As Gentry writes, "symptoms of compassion fatigue are conceptualized not only as disruptive and deleterious effects of caring for the traumatized, but also as a catalyst for positive change, transformation, maturation, and resiliency in the lives of these caregivers" (Gentry, 2002, p.3). This paper will be an exploration of my own change in response to my compassion fatigue: after a break from my job and further study and Buddhist practice, I began my work in the same environment, where similar traumatic stories from my clients provided me with a palpable sense of love, a sense of purpose, an opportunity for transformational meditation practice, and feelings of emotional and physical wellbeing. I attribute my change in experience to my studies of the Buddhist philosophy of mind, a reorientation in my understanding of compassion, a development of my concentration, and increased involvement in Mahayana Buddhist spiritual practices.

\section{Introduction}


Those that work in healthcare professions are known to be at higher risk to develop compassion fatigue, vicarious trauma, secondary stress, secondary traumatic stress disorder, burnout, and secondary traumatization. The fact that there are so many terms that apparently describe the same negative experiences is an indication of the severity and commonality of the problem. Western researchers have made great progress in differentiating these different concepts, explaining their causes and also devising preventative measures and recovery strategies. The goal of this paper is to show how Buddhist teachings on the nature of the mind and our self can explain the causes for these negative experiences from a different perspective, and how Buddhist meditational practices such as compassion cultivation, visualization practices, and tonglen can possibly ameliorate the damages incurred by professionals and perhaps even prevent their appearance. Mahayana Buddhism views compassion not only as beneficial, but a method for attaining enlightenment, an eradication of suffering: "One of the most powerful techniques for developing and maintaining the mind of enlightenment, or bodhichitta, is the meditation known as the exchange of self for others"(Gyatso, 1989, p.196). The same apparent concept of compassion can have two different results: fatigue and burnout on one side, enlightenment on the other. Although the literature contains a large body of research into a phenomena named "compassion fatigue", Buddhist scholars such as Halifax and Makransky assert that the link between genuine compassion and fatigue is a misunderstanding, proposing a renaming of these experiences to "empathic distress"(Halifax \& Solnit, 2019; see also Makransky, 2012). It is confusion about how to practice compassion, its wrongful conflation with empathy, and a misconception about how the "self" exists which causes fatigue, as genuine compassion only increases positive emotions. My use of the term "compassion fatigue" refers to 
the constellation of experiences noted in the western research literature, including feelings of physical, emotional exhaustion, and depersonalization. Nevertheless, due to the problematic nature of this term, I support the renaming of this composite of experiences to Halifax's term of “empathic distress”, because “Compassion does not fatigue!” (Dowling, 2018).

\section{Literature Review}

There are a multitude of concepts that attempt to describe the negative experiences of providers who come in contact with a vast display of human suffering: compassion fatigue, vicarious trauma, secondary stress, secondary traumatic stress disorder, burnout, secondary traumatization. Because all of these terms seem to point in the same general direction of the negative effects that indirect trauma has on providers, I will distinguish the differences between these concepts. In western literature, a definition of compassion fatigue is "the disengagement of caregivers from their patients, which culminates in a reduction or inability to feel empathy and compassion toward patients"(Coetzee, 2017, p.4). According to theorists in the field of psychotherapy, vicarious traumatization (VT) is "the result of cumulative exposure to clients who have been traumatized", while compassion fatigue (CF) is an immediate outcome from a single instance of exposure to a traumatized client (Rodrigo, 2005, p.28, p.22). Secondary traumatic stress (STS) is explained in this field as "the reactions to the stress response of another", while secondary traumatic stress disorder (STSD) is the "culmination of STS" (Rodrigo, 2005, p.18). Burnout, as opposed to CF, and similarly to STSD and VT, unfolds "gradually, increasingly impairing the professional as well as the personal life of the caretaker, in pervasive ways"(Rodrigo, 2005, p.13). The western literature suggests that secondary traumatic stress is a single negative experience, while secondary traumatic stress disorder, vicarious 
traumatization, and burnout are all long-term negative experiences caused by multiple isolated instances of secondary traumatic stress, with the exception of compassion fatigue, which is a long term experience that can be caused by a single instance of secondary traumatic stress. The way in which they develop seems to be the major difference between these similar terms: STS can be dealt with properly and remain a single negative experience, STS can instantly cause compassion fatigue, or multiple instances of STS can gradually cause vicarious traumatization, STSD, or burnout. In other words, if one prevents or successfully manages single instances of secondary traumatic stress, then one automatically prevents the long term results of prolonged exposure to it. In the worst case scenario, a single instance of secondary traumatic stress can propel one into compassion fatigue.

In western literature, compassion fatigue is frequently talked about as "not necessarily a problem, but a natural by-product of caring for traumatized people" (Figley, 1995, as cited in Rodrigo, 2005, p.21). Other researchers in this field say that "the ability to empathize renders the caregiver vulnerable to compassion fatigue" (Coetzee, 2017, p.5), and that "compassion fatigue is the occupational hazard of caring too much" (Gerard, 2017, p.364). There are multiple compassion fatigue models by different authors that frame compassion fatigue as a natural occurrence, which is bound to develop. In these models, the emphasis is placed on the emotional toll of engaging in compassion. The conclusion of these models is that identifying oneself with another's suffering is a sufficient condition for causing fatigue, and it is a generally accepted fact that unpleasant emotions negatively influence health (Fredrickson, Mancuso, \& Branigan, 2011, p.2). 
On the other hand, other western literature suggests that "what causes fatigue is not compassion per se, but the avoidance of anxiety" (Gerard, 2017, p.366), or similarly, that fatigue is caused by "incomplete empathic engagement with trauma survivors and their trauma material"(Pearlman, 2004, as cited in Rodrigo, 2005, p.24). This goes in line with the view that “the denial of therapists' vulnerability or repression might result in a lack of professional vitality, additional projections and burnout"(Rodrigo, 2005, p.54). In this framework, "therapists are urged to begin by accepting, integrating, and remaining aware of their woundedness"(Rodrigo, 2005, p.55). These latter models propose the opposite of the former: the reason for compassion fatigue is not engaging compassion, but failing to engage compassion: "In contrast to the assumption that compassion fatigue arises from too much compassion, historical use of the term suggests just the opposite: compassion fatigue is the result of too little compassion"(Gerard, 2017, p.363). The latter models encourage travel towards uncomfortable feelings with the positive potential outcome of discovering an inner healing pole, and not a negative outcome of fatigue. In this latter framework, contrary to the former, engaging compassion has a healing effect for both the provider and their clients. These models propose that therapists increase their capacity for compassion, and not that they have to be careful about engaging it as it might cause fatigue. It appears that research on the causes of compassion fatigue is mainly split into two sides: on one, the cause of it is an overuse of compassion in clinical practice, while on the other, the cause is underuse of compassion. The conclusion of these latter models is that although engaging in compassion predisposes people to experience unpleasant emotions, inhibiting, or trying to prevent the experience of these unpleasant emotions does more damage than simply experiencing them. This is in line with the general knowledge that repression of emotions leads 
to ill-health: "inhibition of trauma-related thoughts, feelings, and behaviours requires physiological work, leading to autonomic arousal in the short term and placing cumulative stress on the body in the long term" (Cromby \& Ellis, 2009, p. 3). The former models inform us that someone is at risk of fatigue because of allowing oneself to experience negative emotions, while the latter models advise against suppressing these negative emotions, as that also leads to fatigue. Apart from this split, there are other theories in occidental literature that suggest compassion fatigue has as cause the "motive to right the wrong of an earlier hostility" (Gerard, 2017, p.365). In this view, practitioners are unconsciously motivated towards altruism by their earlier opposite attitudes of egoism, and they unconsciously sacrifice themselves by experiencing compassion fatigue. In this instance, practitioners do not empathize with their clients, but instead identify with their former selves which caused suffering similar to the one now displayed by their clients. They are not overwhelmed by the negative emotions of their clients but overwhelmed by their own emotions of guilt, shame and remorse. This hypothesis proposes that when altruistic work is motivated by selfish motives, engaging in compassion is not possible, as one is overinvolved with their own feelings and memories. Being in a role where one is expected to help, one develops symptoms of compassion fatigue to compensate for their lack of supportive involvement. This model informs us of the role motivation plays in compassion engagement and urges practitioners to analyze their altruistic intentions for any selfish involvement. Although the author recognizes that "it would be a severe overgeneralization to assume that all who suffer from compassion fatigue harbor unconscious hostility", his theory points to the fact that the role of the compassionate caregiver does not allow feelings of hostility for the client. Since hostility can be an appropriate emotional response to someone causing harm, professionals are urged to 
avoid seeing clients as causing them harm, regardless of the emotional distress they experience as a result of listening to their stories.

Rodrigo posits that what contributes to the development of compassion fatigue is "the presence/absence and depth of a personal philosophical framework[...]which provides meaning and hope in the face of suffering, evil and injustice" (Rodrigo, 2002, p.95). As healthcare professionals meet more people affected by adversities than professionals in other fields, their personal philosophies will be challenged continually. Because providers are always surrounded by others that are victimized in one way or another, it is important for them to develop a philosophy that does not further victimize their clients. For example, some argue that "the use of psychiatric diagnosis increases stigma, does not aid treatment decisions, is associated with worsening long-term prognosis for mental health problems"(Timimi, 2014, p.1). This framework proposes that providers pay attention to how socially accepted practices such as diagnostics, involuntary commitment, and use of psychotropic medication affect their relationship with their clients.

Other factors that likely play a part in the development of compassion fatigue are: a personal history of trauma, negative coping mechanisms such as "using drugs or alcohol, attempting to forget about clients' disclosures of traumatic material, acting out aggression against significant others, and withdrawing from others" (Follette, Polusny, \& Milbeck, 1994, p.277). The training of therapists is considered of major importance (Pearlman, \& Ian, 1995, p. 564). Additionally, impractical beliefs about the solvability of clients' problems, the one-sidedness of the therapeutic relationship, the difficulty in measuring success in clients, the pervasiveness of apparent failure in clients, the bureaucratic responsibilities of providers, overincreased 
association with clients, and the work environment are all sources of stress that can lead to compassion fatigue (Rodrigo, 2005, p.8). A study on the efficacy of psychotherapy found that $40-60 \%$ of patients do not recover from their mental disorders(Curran, et al. 2019, p.1).

Expecting recovery can be a source of stress when its absence is used to question the providers' professional competence, but the reality of the number can be stress-inducing in itself. It was also found that "many of those suffering with compassion fatigue symptoms maintained an other-validated stance in their caregiving work", which is an additional source of stress when external validation is not received. (Gentry, 2002, p.26). Compassion fatigue is a complicated condition that comes as a result of a large number of interrelated factors, as the jobs that predispose people to compassion fatigue have numerous sources of stress.

Before I present the Buddhist alternative to the occidental view of compassion, I want to note that the sources I make use of for Buddhist concepts and practices are mainly from western, contemporary, English-writing authors who are drawing from Mahayana, Vajrayana, and Theravada Buddhist schools. Some of these authors and teachers underwent traditional training in the original-language Buddhist scriptures, while other academics employ their knowledge of psychology to make connections to ancient Buddhist thought.

According to a Buddhist view, compassion is not a source of stress: "In fact, some neuroscientists and social psychologists say that "compassion fatigue" is empathic overarousal and distress. Compassion does not fatigue us - it is a source of strength, and supports our thriving and benefits others" (Halifax \& Solnit, 2019). Because the mind is understood to be in charge of our subjective experience, Buddhist psychology argues that a compassionate mind supports our welfare, as it is "much more closely attuned to our actual condition" (Makransky, 
2012, p.1). By our actual condition, Makransky refers to the idea that compassion is our natural state of mind which arises effortlessly once we become disillusioned with our false sense of permanent, independent self. A major aspect of the Buddhist concept of compassion is the broadness of suffering that it encompasses: one can engage a compassionate mind not only when helping oneself or another to go through obvious suffering such as a traumatic experience.

The Buddha discovered two other types of suffering: of transience and of self-centered conditioning. The suffering of transience refers to our incessant desire for pleasant experiences, circumstances and material things (Makransky, 2012, p.3). However, these are not a source of lasting wellbeing, a concept similar to the western hedonic adaptation: they are likely to temporarily increase happiness, but there is always a return to baseline. One can engage a compassionate mind by becoming aware of this continuous desire and loss, and realizing that all humans experience this common suffering.

The third form of suffering, self-centered conditioning, is believed to be the most subtle: according to a Buddhist view, from an impermanent stream of experience the mind is conditioned to create "the impression of a substantial, unchanging, and separate sense of self surrounded by a stable world"(Makransky, 2012, p.3). Because of this nature of our mind, we become attached to whatever maintains this illusion, and become fearful to whatever denies it. This unconscious movement back and forth between attachment and fear is another type of suffering that can allow us to become compassionate. Having awareness of these three types of suffering can possibly aid in creating a more realistic reaction to the obvious suffering that health professionals observe in their clients. Also, according to the third type of suffering, others' stories of trauma and suffering deny the illusion of a permanent, independent self and a stable 
world, creating fear, which can explain the development of CF, STSD or burnout. The Buddha's teachings show how we are out of touch with reality by fabricating illusions of permanence and self. Through understanding how one personally fabricates these using mindful awareness, one recognizes that all others do the same, and compassion is revealed. In short, compassion in Buddhism is cultivated by becoming aware of our personal suffering. While this is similar to Rodrigo's idea that professionals should remain in touch with their woundedness (Rodrigo, 2005, p.55), the Buddhist approach refers to the more subtle suffering of self-centered conditioning, and gives specific instructions for how to get in touch with it: watch for how the mind fabricates illusions of permanence and self. Apart from this understanding, in Buddhist traditions, compassion is one of the four immeasurables "which are said to give the mind tremendous power to overcome obstacles, to live with happiness and ease, to support one's progress in all aspects of the path, and to elicit the potential in others for similar states of mind"(Makransky, 2012, p.6). Following the meditation instructions for developing these immeasurables gradually familiarizes the mind with them, as it will be explored in the following paragraph.

The first immeasurable, love, is first developed towards oneself by generating strong feelings of love using repetition of phrases such as "May I have well-being and happiness; May I be free from enmity and danger'(Makransky, 2012, p.6). Gradually, this is extended more and more until it encompasses everyone: first to a mentor or friend, then to a stranger, then to a hostile person: "this draws our mind into a state of deep absorption, with a sense of immeasurable inclusiveness, stability, tranquility, and joy”(Makransky, 2012, p.7). The second immeasurable, compassion, is based on the development of this love towards all beings. However, compared to western views which propose that $40-60 \%$ of patients do not recover 
from their mental disorders(Curran, et al. 2019, p.1), "inner freedom from suffering is seen as a real possibility within the Buddha's path of awakening” (Makransky, 2012, p.7). I suspect adopting this positive prospect can be beneficial for mental health professionals. However, it might also be considered an impractical belief about the solvability of a clients' problems. In this case, one or the other can be true, but not both: either people have the possibility of complete healing, or people are cursed to a life of suffering. Buddhist belief is that complete eradication of suffering is possible, but it is also acknowledged that consistent effort is needed to achieve it. While most Buddhist traditions stress the importance of a guru, inner work must be done by the student. Similarly, therapists are not solely responsible for the healing of their clients. For a therapist to think that they are the sole reason behind their client improving or not is self-centered. However, adopting the stance of impossible release from suffering must also take its toll, as it is not as motivating and energizing to have as a goal making life bearable for clients. In contrast, the goal of Buddhist practice is complete eradication of suffering, peace, and ultimate, lasting happiness. Adopting a framework of striving for complete wellness as opposed to striving for management of symptoms can mitigate this factor that contributes to the development of CF.

Because of the previous cultivation of love towards all beings, "reflecting on the sufferings they undergo, compassion for them naturally arises”(Makransky, 2012, p.7). One is instructed to practice compassion first towards oneself, then towards friends, strangers, hostile people, and ultimately, every being, with the important distinction that even those that do not experience obvious suffering still experience the suffering of transience and of self-centered conditioning. The third immeasurable, sympathetic joy, prevents jealousy and arises naturally 
because of the cultivation of love and compassion for all beings. As with the previous two immeasurables, one is instructed to bring to mind the happiness of a friend, the happiness of a stranger, the happiness of an enemy, and ultimately, the happiness of all beings. Although the suffering of transience shows us that we suffer because of chasing impermanent happinesses, one can still benefit from contemplating such fleeting moments. The fourth and final immeasurable, equanimity, is a "peaceful calmness in the face of the ups and downs that all beings undergo, recognizing that their potential for happiness and suffering is conditioned by their own patterns of intention and reaction to experiences"(Makransky, 2012, p.8). Buddhism stresses that the root of any suffering is internal: ultimately, there are no external causes that can stop one from becoming Enlightened. This is in contrast with the biomedical model which states with no credible evidence that mental disease has biological, genetic causes(Deacon, 2013, p.847). Comparatively, the biomedical model is victimizing, while the Buddhist model is empowering: "the underlying cause of mental illness is an individual's belief that they inherently exist" (Van Gordon, Shonin, Griffiths, 2017, p.1). Equanimity is also understood to have the quality of preservation of the previous three immeasurables, and the practice of these four immeasurables is said to enable the practitioner to experience happiness similar to that of the Gods. (Makransky, 2012, p.8)

The Buddhist understanding of the so-called compassion fatigue that takes into account all the various apparently contradicting western conceptual frameworks can be understood by analyzing the Yogachara school of Buddhist philosophy. According to a non-idealist interpretation of it, "our experience can be completely accounted for by factors within consciousness itself, and that it is not necessary to posit any external objects" (Kellner \& Taber, 
2014, p.712). What this means is that humans do not perceive reality, but a personal interpretation of reality, based on beliefs which are constructed in the mind based on past personal experiences, their repetition and vividness. A personal interpretation of reality leaves traces in the mind which activate when a similar phenomena occurs. Yogacharins named these traces "seeds", which reside in the "store-consciousness". This means that what one perceives to be "out there" is actually created by previous seeds, therefore non-existent in the way one perceives it. Holding on to this realization without entertaining the idea that there is in actuality something external that has the proprieties one posits is enlightenment(Shen \& Tran, 1995, p. 24). Western researchers of compassion fatigue frame it as being caused by an involvement with an external object, be it over engagement or under engagement of compassion, a personal history of trauma or the numerous others. In contrast, the Yogachara explanation for the so-called compassion fatigue is that all of these different factors can contribute to the development of empathic overarousal and distress, but not to compassion fatigue. The western beliefs of the causality of CF assert the existence of negative experiences that directly lead to the development of CF. On the other hand, the Yogachara perspective opens up the opportunity to address those negative experiences with the understanding that they do not have anything intrinsic to them that can cause CF. For example, during the training I received before starting my job, I was warned of the capacity of my position to cause compassion fatigue. The whole training was built around the idea that one has to be very careful with their involvement with traumatized others. This is in contrast to the Buddhist approach with suffering others, taken from a book on mind training "I will cherish beings of bad nature, and those oppressed by strong negativities and sufferings, as if I had found a precious treasure very difficult to find" (Rimpoche Gelek, 2011, p.96). The training 
I received from my job contained repetitions of the idea that engaging with suffering others is harmful and dangerous. During my job, the reality I experienced was based on this belief: hearing stories of traumatic experiences, I experienced empathic overarousal, emotional distress, and physical depletion. The Buddhist mind training I engaged in ulteriorly spoke beautifully of engaging in compassion, and framed it as an opportunity for wellbeing. Although I had the same job, and engaged with more or less the same suffering, my reality was now a deep felt sense of love and wellbeing. Belief creates reality. The Yogachara school of philosophy explains compassion fatigue as an unconsciously self-created reality, based on beliefs and personal experiences stored in the store-consciousness. Thus, it takes into account all the causes for compassion fatigue, even the contradictory ones, and also asserts that they are relative truths, which stand only as long as one believes in them as independent and externally existent. It asserts that we live in our minds, and not in the outside world. What is needed to change our experience is not a change of world, but a change of mind. To mitigate compassion fatigue, health professionals can use all the western research in what causes it, and compare it to their personal beliefs. Whenever personal beliefs match a research framework, one can then inquire about what makes them adopt this belief. One's experience of reality is based on personal beliefs which can be adopted from others' beliefs such as compassion as a source of stress. Simply being aware that one's experience of reality is based on unreliable sources can be enough for a complete change in experience. When it is not, Buddhist practices and modes of inquiry can help facilitate such a change.

\section{How is compassion different from empathy and sympathy?}


It was acknowledged that research in the field of compassion fatigue is hindered by the ambiguity of the term (Coetzee, 2017, p.4), and "although sympathy, empathy, and compassion are used interchangeably and frequently conflated in healthcare literature, patients distinguish and experience them uniquely"(Sinclair, et al., 2016, p. 438). In fact, "some neuroscientists and social psychologists say that compassion fatigue is empathic overarousal and distress" (Halifax \& Solnit, 2019, p.58). In a study on the differences between these three concepts, sympathy was defined as "an unwanted, pity-based response to a distressing situation, characterized by a lack of understanding and self-preservation of the observer", empathy as "an affective response that acknowledges and attempts to understand individual's suffering through emotional resonance", and compassion as having "enhanced the key facets of empathy while adding distinct features of being motivated by love, the altruistic role of the responder, action, and small, supererogatory acts of kindness"(Sinclair, et al., 2016, p. 437). These definitions work alongside the Buddhist understanding of compassion: "We sense others' suffering as like our own and naturally wish them deep freedom from it'(Makranski, 2012, p.1). The main difference is that in empathy, one acknowledges and imagines the suffering in the other, while in compassion one takes the further step of intentionally generating feelings of love, kindness, concern, and altruism. This might seem like a minor step, but it apparently makes the difference between compassion fatigue and its absence: In an fMRI experiment run by Tania Singer at the Max Planck Institute in Germany with Matthieu Ricard, a Tibetan Buddhist monk, the difference between generating compassion and empathy was observed both on brain scans and from Matthieu's described experience: "Brain scans showed that his experience of empathy had registered in the neural networks associated with pain[...]Whereas the compassion phase of his experience had registered in 
different neural networks — those associated with positive emotion, maternal love, and feelings of affiliation[...]Matthieu described his experience during the compassion meditation as a warm, positive state coupled with a strong desire to be of service to the children. This was in distinct contrast to his earlier experience with empathy (actually empathic distress), which was completely draining and debilitating” (Halifax \& Solnit, 2019, p.71). It appears that the literature on compassion fatigue does not make a clear differentiation between empathy and compassion, as the results of the study show that empathy is responsible for fatigue and compassion for wellness. Also important to note is that the subject in this study was an expert meditator. It is safe to assume that his meditation training allowed him to experience such differences between compassion and empathy. Buddhist practices that can help one achieve a state of mind in which compassion is a source of wellness will be explored.

\section{Needs of clinicians are unmet}

Health professionals face a vast array of suffering. How well they manage their personal histories of trauma in relation to their clients, their internal and external resources, motivations, environment, personal and emotional development all have the capacity to either support or undermine their wellbeing and their efficiency. The training that professionals undergo should prepare professionals to face a vast array of suffering, but it is recognized that "in virtue of their chosen career paths, [they] naturally want to help and heal others, and yet their formal education leaves them emotionally ill-equipped to do so"(Gerard, 2017). For example, empathy, congruence and unconditional positive regard are known as the three necessary and sufficient conditions in a Carl Rogers' person-centred approach to therapy (Kirschenbaum, \& Jourdan, 2005). There is no mention of compassion, which as seen in the previous section, has a very 
different internal effect compared to empathy. This promotion of empathy as opposed to compassion is detrimental to health care professionals, as "many researchers[...]have suggested that empathy is a more complex concept than Rogers and others have recognized" (Kirschenbaum, \& Jourdan, 2005, p. 42).

Because of the mind's tendency to cling to whatever creates a stable sense of self (Makransky, 2012, p.3), it is important to counteract this tendency with inquiry without reference to what causes one to experience reality as they do. The use of diagnostics (CF, VT, STSD) is a further step in creating a false sense of stability. A self with compassion fatigue is a stable sense of self, which validates beliefs and feelings, making them appear solid and true. The western approach to mental health care is concept driven. The use of diagnostics is an example of that: whether mental conditions are believed to be caused by an unproven chemical imbalance(Brett, 2013, p.847) or by early life experiences, holding either of these as certain is an example of the mind's tendency to create a sense of stable world. Having answers to human problems in the form of diagnostics based on presuppositions that are generally accepted by society can be harmful, and can prevent one from further investigation. The process of investigation itself goes against the mind's tendency to create a sense of stability. The mind finds comfort in concepts and labels such as diagnostics and in discovering the causes for an apparent problem.

Conceptualizing the experience with the label of a problem is a settling in itself, and takes away curiosity. The Buddhist practices that will be described in the following sections have the power to restore this curiosity and uncertainty.

\section{The training of a Bodhisattva}


In Mahayana Buddhism, a Bodhisattva "willingly delays final nirvāṇa and takes practically limitless additional rebirths for the benefit of sentient beings"(Harris, 2015, p.203). The most important step the Bodhisattva takes is "eliminating their innate belief in self before taking on demanding tasks to aid others"(Harris, 2015, p.203). Realization of no-self is what seems to protect Bodhisattvas from CF, VT, STSD and burnout: "Because of her mental training, the Buddhist practitioner advanced in the knowledge of selflessness experiences a far smaller decrease in well-being than the ordinary person undergoing the same apparent hardships"(Harris, 2015, p.210). However, full realization of selflessness is understood to be gradual and taking a long amount of time: "The whole idea of being a no self takes the Western mind ages to penetrate and to be realized" (Michalon, 2001, p.206). When one experiences unpleasant emotions as a result of empathizing with another, one finds oneself outside of the usual reference point of "self" one forgets who one is, and instead identifies with another. As one usually identifies with their own feelings or thoughts, empathy makes one identify with the feelings and thoughts of another. From this identification, the empathizer has an immediate, direct change of experience: one feels differently, sees the world differently, and sometimes even experiences the same symptoms as his clients. Engaging in empathy shows us that there is no inherent, independent self. The Five-Aggregate Budhist model of mind can also be used to aid in this realization, which will be described in the following section.

\section{The Five-Aggregate Buddhist Model of Mind}

"The five-aggregate model of the mind describes subjective conscious experience from a first-person perspective" (Karunamuni, 2015, p.1). The framework of the five skandhas is of particular importance in understanding how one can make the decision to engage in compassion 
as opposed to empathy. By working with one's experience in this framework, "the emotions are being progressively disclosed as no more belonging to passive experience, but as varieties of active behavior" (Paribok, 2019, p. 2019). This is especially important as I mentioned before that some western research suggests simply engaging compassion is bound to cause fatigue. Using this model can make the difference between seeing oneself as a passive receiver of fatigue, to seeing how one is playing an active role in their experience of fatigue. This five-fold model is composed of rūpa, vedanā, saṃjñā, sañkhāra, and vijñāna. Rūpa refers to the five senses: sight, hearing, touch, smell, taste. This model proposes that the information from our senses is not perceived objectively, but through "interpretation and recognition" (Paribok, 2019, p. 2019). The second element, vedanā, refers to the subtle internal experience that arises after making contact with information from the five senses: it can be pleasant, unpleasant, or neutral. The third skhanda, samjuñā, is where meaning is ascribed to the five senses using language, mental imagery, associations, expectations and memories. The fourth aggregate, sañkhāra, refers to emotional states (happiness, sadness, anger etc.). The fifth and final one, vijñāna is said to be the "act of choosing a sensory channel” (Paribok, 2019, p. 2020).

In my personal journey of using this five-fold model, I stopped thinking that external phenomena can objectively cause me emotional reactions. Instead of believing that listening to a client's story has the power to cause me feelings of discomfort, I started entertaining the idea that my own interpretation and specific focus of attention cause me discomfort. I observed how contact with a client's traumatic story and my focus on imagining myself in their position triggered a non-pleasant subtle feeling, which triggered self-created negative associations and expectations, which energized unpleasant feelings: sadness for the client, anger at whoever 
caused this suffering, fear for the client's safety, a sense of being overwhelmed. My feelings, then, were based not on an objective reality, but on my own subjective interpretation of reality. I saw that it was not the external phenomena that caused me feelings, but my interpretation and focus of attention of said external phenomena. That makes them internal phenomena: "neither sensations nor thoughts of other persons and living beings are given to any of us directly, we are irrevocably confined within ourselves"(Paribok, 2019, p. 2018). Experiencing a multitude of emotions without the recognition of my role in making them emerge is bound to cause fatigue. I felt as if I was being thrown around to unpleasant sensations and states of mind, and was trying to focus on them because of the underlying false belief that I needed to empathize in this way with my client in order to be of help. I saw that it was my focus on generating empathy that made me experience the feelings of my client, and that focusing instead on generating love and a desire for them to be free of this suffering would give me something a lot more pleasant and useful to keep my mind on. I started building up my capacity for compassion and for single pointed concentration, which will be discussed in the following sections. These allowed me to remain with my internal experiences for longer periods of time, instead of being thrown from one to another or trying to escape them because of being overwhelmed. I went from reacting to external stimuli to discovering how I was actively (and previously unconsciously) participating in creating my reactions. I started asking myself what meaning I attribute to the stimuli and if the meaning is useful, with the underlying understanding that the meaning I place my attention on affects my emotional reactions.

I discovered that my experience of anger at whoever caused my client harm was motivated by my preconceived notions of a victim and an offender. While these roles might have 
been true for a point in time, I chose to maintain my focus on a broader time perspective, with an understanding that the offender is or was also a victim at one point in time. Staying with this broader-time perspective allowed me to experience compassion instead of anger, and this feeling is broader, more spacious and softer than anger. Instead of being overwhelmed with the unpleasant feeling of sadness for my clients, with the help of my compassion meditation practice, I began to utilize the arising of the feeling of sadness as a springboard for compassion. Instead of focusing solely on the sadness that arose from listening to their story, I started placing my attention on the experience that surfaced from wishing them to be free of the suffering they were relating. This also created an internal space much more freeing, lighter than the heavy experience of sadness. I also observed how my experience of fear surfaced from a presumption of my clients as victims both now and in the future, a presumption that stemmed from an attitude of helping as opposed to serving, prompting the view that my clients are weak. Instead of seeing them as such, I chose to focus on my already existing belief in their ability to strive against negative life circumstances. This change in perspective freed me up to being motivated by trust in my clients. Instead of placing my attention on anger, I focused on the broader time perspective and placed my attention on the feeling of compassion that naturally arose. Instead of placing my attention on the sadness, I placed it on what feeling arose after wanting them to be free of their suffering. Instead of placing my attention on the fear, I placed it on trust. By generating feelings of love and changing where I put my attention, I felt in control of where my mind went, and used the energy of the unpleasant sensations to launch me to more beneficial points of attention. In this way I transformed my internal experience of being overwhelmed, angry, sad and afraid, to 
feeling a sense of wellness, love, kindness and trust. I began relating to my clients differently, and there was a newfound lightness in the room.

\section{Shamatha- Single pointed concentration}

"During Shamatha practices, mindfulness - or the faculty of focusing continuously upon a familiar, chosen object without distraction, according to traditional Buddhist texts—is trained, and the practitioner develops the ability of keeping focused attention on a given object, such as the breath"(Kozasa et al, 2015, p.2). This type of meditation is seen as a prerequisite for tonglen, a compassion meditation: "sitting meditation and tonglen always go hand in hand" (Chödrön, 2001, p.21). The reason for this is that the meditator, after practicing Shamatha, can more effectively maintain their concentration on their breath, which is of major importance in tonglen. Shamatha is also useful in building a capacity for tolerating difficult thoughts: "Instead of becoming angered, frustrated, or saddened by difficult thoughts and, subsequently, aggressively challenging them, Shamatha teaches the individual to be open to, accepting of, and even compassionate towards such thoughts"(Pardy, 2016, p.10). Considering that a symptom of CF is intrusive thoughts (Gentry, 2002, p.3), shamatha training can be particularly useful for mitigating it. I also found it useful to have the ability to remain concentrated on a chosen object of awareness when practicing the deity meditation of Chenrezig, which will be discussed in the following section.

\section{Chenrezig- Tibetan Deity of Compassion}

In Tibetan Buddhism, Chenrezig can be looked at from two perspectives: a regular person that through practice developed immeasurable compassion, or "as compassion embodied in the form of a deity" (Ringu, 2011, p.2). The Chenrezig deity practice is a method for getting a 
personal taste of how compassion feels, it is a method of learning through emotional involvement. By visualizing Chenrezig, one gets in touch with a presence "of complete perfection, of somebody without any fault or confusion, who has done away with ignorance, who is totally wise and completely compassionate, who only wants to help and work for the welfare of other beings with no other intention, no selfish motivation"(Ringu, 2011, p.4). The most important aspect of the practice is emotional and physical involvement: one does not have to try to visualize Chenrezig as clearly as a picture, but experience personally how their loving-kindness and compassion affects one's state of being. The actual practice begins with taking refuge, which symbolizes setting the goal of attaining Enlightenment for the benefit of others: from the very beginning, compassion is evoked. This is repeated three times, setting a powerful mental imprint of purpose, which gives one energy and motivation for practice. Then, the actual visualization begins: a lotus flower appears on top of one's head, then a moon disk, then the letter "HRI", which emanates lights and from which the deity appears. Even the very first time I practiced, this visualization triggered moments of intense emotional and physical bliss. The visualization gets more intricate, with symbols such as a wish fulfilling gem, crystal rosary, white lotus, syllables that emit light, long mantra recitations, prayers, and directions for visualization of the deity on top of other's heads. The practice ends with dedication, which is a reminder for the compassionate goal set in the beginning. To investigate the complexity of this practice would take an entire book, and is outside the scope of this paper. However, practicing the Chenrezig meditation and visualization greatly increased my wellbeing while working with adolescents. Hearing stories of trauma, behaviour or emotional struggle would trigger similar blissful feelings that I would experience during practice, although less intense and of shorter 
duration. Hearing the difficulties of my clients seemed to trigger a short moment of empathic arousal, then compassion immediately after in this new form of physical and emotional wellbeing. This was in complete contrast with my history of client's stories only triggering empathic arousal, a sense of hopelessness, sadness and fear. After discovering this, I started consciously visualizing Chenrezig on top of my head and on the head of my clients, which put me in touch with a sense of increased compassion, and took away the feeling of one-sidedness of my relationships with them: they were now opportunities for cultivating a compassionate presence. This practice also took away my tendency for overinvolvement: I was no longer alone with my clients, solely responsible for creating a healing environment. I felt as if I had an invisible new work colleague, a true master at caring for others, who guided me and provided me with reassurance. I noticed changes not only in myself, but also in my clients: they seemed to have an easier time relating to me, trusting me, reaching out to me when they needed help, and disclosing their difficulties. Considering that mental imagery techniques have been proven successful in the field of sports for reducing muscle fatigue, improving strength and performance (Slimani, Tod, Chaabene, Miarka, Chamari, 2016, p.1), and my personal change from empathic overarousal to compassionate wellbeing, I think the Chenrezig meditation and visualisation practice needs further investigation as a preventative measure for CF, STSD and burnout.

\section{Tonglen}

Tonglen is a Tibetan Buddhist practice that consists of visualisation combined with breath awareness. The inhale is combined with a visualisation of taking in whatever is negative from others (for example, the suffering of a client relating a traumatic story), and the exhale is merged with visualisation of positive qualities being given to others (for example, compassion and relief 
from suffering of the client). This exercise can be done either while in direct contact with others (tonglen on the spot) or as a formal meditation practice. Previous research on the benefits of tonglen found it useful for therapists "with regards to burnout prevention" (Pardy, 2016, p.25). Practice of tonglen was also shown to increase self-compassion in a study done on beginner non-Buddhist meditators that involved three formal 18-minute tonglen sessions, 48 hours apart (Pardy, 2016, p.26). For me, tonglen is a tool for affect regulation. Already experiencing the effects of my Chenrezig practice, tonglen on the spot synchronized my internal feelings of wellbeing with the outbreath, and thus provided me with a tool for consistently and reliably experiencing the benefits of arousing compassion. The in-breath became a conscious identification with the suffering of my clients, and the outbreath was a complete release of it. Previous to this, compassion fatigue as "the disengagement of caregivers from their patients"(Coetzee, 2017, p.4) was already set in motion because my personal fear of their suffering negatively affecting me resulted in conscious attempts of detachment. With the discovery of this practice, I was no longer fearing that the suffering of my clients can negatively affect me: the practice of inhalation of negativity, and subsequently reliable release from this negativity proved to me that I can empathize with my clients without any negative side effects. Similar effects were reported by participants in Pardy’s study: “experiences of calmness and relaxation; heightened abilities of addressing chaotic, challenging experiences; and the dissolving of difficult emotions[...]some felt that tonglen energized them"(Pardy, 2016, p.62). Tonglen can prevent incomplete empathetic engagement, which is seen as a possible cause for compassion fatigue (Rodrigo, 2005, p.24). The mechanism that serves this function is the instruction for complete empathetic engagement by the breathing-in of negative emotions. The 
practice of Tonglen can also mitigate empathic overarousal and distress, which other researches see as the reason behind compassion fatigue(Halifax \& Solnit, 2019). The outbreath provides reliable release from arousal, thus preventing excessive strain on the nervous system.

\section{Conclusion}

The Buddhist practices that mitigate compassion fatigue focus on developing a present, and continual non-dual awareness in regards to how professionals fabricate their view of reality, and cultivation of compassion and of the ability to engage it as an alternative to empathy. The western explanations for compassion fatigue assume the self as existent and focus on developing methods for the construction of this self in ways that alleviate fatigue. Buddhist texts frame compassion as a source of happiness, while the western understanding is that compassion drains internal resources. Tonglen was previously acknowledged as a possible preventor of burnout(Pardy, 2016, p.25). However, the practice of Chenrezig visualisation and meditation and the 5-aggregate model of mind have not yet been explored in regards to their capacity to alleviate stress that can lead to development of CF, STSD, or VT. Considering the benefits from my personal experience with these practices, they deserve further research in the field of compassion fatigue. The term of "compassion fatigue" is problematic because compassion promotes wellbeing and positive emotions, so the association with fatigue is contradictory and misleading. It is empathy that has the potential to elicit negative emotions, which is why I support the disuse of the term CF. 


\section{REFERENCES}

Chödrön Pema, \& Ötro Tingdzin. (2001). Tonglen: the path of transformation. Vajradhatu Publications.

Coetzee, S. K., \& Laschinger, H. K. S. (2018). Toward a comprehensive, theoretical model of compassion fatigue: An integrative literature review: Theoretical model of compassion fatigue. Nursing \& Health Sciences, 20(1), 4-15.

https://doi.org/10.1111/nhs. 12387

Curran, J., Parry, G. D., Hardy, G. E., Darling, J., Mason, A.-M., \& Chambers, E. (2019). How Does Therapy Harm? A Model of Adverse Process Using Task Analysis in the Meta-Synthesis of Service Users' Experience. Frontiers in Psychology, 10, 347. https://doi.org/10.3389/fpsyg.2019.00347

Deacon, B. J. (2013). The biomedical model of mental disorder: A critical analysis of its validity, utility, and effects on psychotherapy research. Clinical Psychology Review, 33(7), 846-861. https://doi.org/10.1016/j.cpr.2012.09.007

Dowling T. (2018). Compassion does not fatigue!. The Canadian veterinary journal = La revue veterinaire canadienne, 59(7), 749-750.

Ellis, D., \& Cromby, J. (2009). Inhibition and reappraisal within emotional disclosure: The embodying of narration. Counselling Psychology Quarterly, 22(3), 319-331. https://doi.org/10.1080/09515070903312975

Fredrickson, B. L., Mancuso, R. A., \& Branigan, C. (2011). The Undoing Effect of Positive Emotions. 20. 
Follette, V. M., Polusny, M. M., \& Milbeck, K. (1994). Mental health and law enforcement professionals: Trauma history, psychological symptoms, and impact of providing services to child sexual abuse survivors. Professional Psychology: Research and Practice, 25(3), 275-282. doi:10.1037/0735-7028.25.3.275

Gentry, J. E. (2002). Compassion Fatigue: A Crucible of Transformation. Journal of Trauma Practice, 1(3-4), 37-61. https://doi.org/10.1300/J189v01n03 03

Gerard, N. (2017). Rethinking compassion fatigue. Journal of Health Organization and Management, 31(3), 363-368. https://doi.org/10.1108/JHOM-02-2017-0037

Harris, S. E. (2015). Demandingness, Well-Being and the Bodhisattva Path. Sophia, 54(2), 201-216. https://doi.org/10.1007/s11841-015-0474-0

Karunamuni, N. D. (2015). The Five-Aggregate Model of the Mind. SAGE Open, 5(2), 215824401558386. https://doi.org/10.1177/2158244015583860

Kellner, B., \& Taber, J. (2014a). Studies in Yogācāra-Vijñānavāda idealism I: The interpretation of Vasubandhu's Vimśikā. Asiatische Studien - Études Asiatiques, 68(3). https://doi.org/10.1515/asia-2014-0060

Kirschenbaum, H., \& Jourdan, A. (2005). The Current Status of Carl Rogers and the Person-Centered Approach. Psychotherapy: Theory, Research, Practice, Training, 42(1), 37-51. https://doi.org/10.1037/0033-3204.42.1.37

Kozasa, E. H., Lacerda, S. S., Menezes, C., Wallace, B. A., Radvany, J., Mello, L. E. A. M., \& Sato, J. R. (2015). Effects of a 9-Day Shamatha Buddhist Meditation Retreat on Attention, Mindfulness and Self-Compassion in Participants with a Broad Range of 
Meditation Experience. Mindfulness, 6(6), 1235-1241.

https://doi.org/10.1007/s12671-015-0385-8

Makransky, J., PhD. (2012). Compassion in Buddhist Psychology. Compassion and Wisdom in Psychotherapy

Michalon, M. (2001). "Selflessness" in the Service of the Ego: Contributions, Limitations and Dangers of Buddhist Psychology for Western Psychotherapy. American Journal of Psychotherapy, 55(2), 202-218.

https://doi.org/10.1176/appi.psychotherapy.2001.55.2.202

Pardy, J. (n.d.). The Tonglen Experiences of Individuals with Established Sitting Meditation. 126.

Paribok, A. V. (2019). Study on a Correct Interpretation of the Buddhist Notion of "Skandhas." Proceedings of the 4th International Conference on Contemporary Education, Social Sciences and Humanities (ICCESSH 2019). Proceedings of the 4th International Conference on Contemporary Education, Social Sciences and Humanities (ICCESSH 2019), Moscow, Russia. https://doi.org/10.2991/iccessh-19.2019.431

Pearlman, L. A., \& Ian, P. S. M. (n.d.). Vicarious Traumatization: An Empirical Study of the Effects of Trauma Work on Trauma Therapists. 8.

Rimpoche, Gelek (2011). LOJONG Mind Training in Eight Verses A Commentary on Geshe Langri Tangpa's Famous Root Verses (Jewel Heart Transcript). Nijmegen, Netherlands: Jewel Heart. doi:tsemrinpoche.com Ringu Tulku Rinpoche_Chenrezig_The Practice of Compassion (2011, RigulTrust Publications)_Libgen.lc.pdf. (n.d.). 
Rodrigo, D., \& Maria, W. A. (n.d.). Conceptual dimensions of compassion fatigue and vicarious trauma. 191.

Shen, Q., \& Tran, V. D. (Eds.). (1995). Philosophy of science and education: Chinese and European views. Council for Research in Values and Philosophy.

Sinclair, S., Beamer, K., Hack, T. F., McClement, S., Raffin Bouchal, S., Chochinov, H. M., \& Hagen, N. A. (2017). Sympathy, empathy, and compassion: A grounded theory study of palliative care patients' understandings, experiences, and preferences. Palliative Medicine, 31(5), 437-447. https://doi.org/10.1177/0269216316663499

Slimani, M., Tod, D., Chaabene, H., Miarka, B., \& Chamari, K. (n.d.). Effects of Mental Imagery on Muscular Strength in Healthy and Patient Participants: A Systematic Review. 17.

Timimi, S. (2014). No more psychiatric labels: Why formal psychiatric diagnostic systems should be abolished. International Journal of Clinical and Health Psychology, 14(3), 208-215. https://doi.org/10.1016/j.ijchp.2014.03.004

Van Gordon, W., Shonin, E., \& Griffiths, M. D. (2017). Buddhist emptiness theory: Implications for psychology. Psychology of Religion and Spirituality, 9(4), 309-318. https://doi.org/10.1037/rel0000079 